\title{
A Review of the Condition of OPD Patients in Arba'een On-foot Pilgrimage in 2019
}

\author{
Leila Mohammadinia ${ }^{1,2,3}$ (D), Mehrab Sharifisadeh ${ }^{4,5, *}$ (D) Hadi Lashkari ${ }^{6}$, Farid Moradian ${ }^{7}$ and Hamid \\ Choobineh $^{8}$ \\ $1 \mathrm{PhD}$ in Health in Disasters and Emergencies, Trauma Research Center, Shahid Rajaee (Emtiaz) Trauma Hospital, Shiraz University of Medical Sciences, Shiraz, Iran \\ 2 Research Center for Emergency and Disaster Resilience, Red Crescent Society of the Islamic Republic of Iran, Tehran, Iran \\ 3 Department of Health in Disasters and Emergencies, Health and Human Resources Research Center, School of Management and Information Sciences, Shiraz \\ University of Medical Sciences, Shiraz, Iran \\ 4 Research Center for Health Management in Mass Gathering, Red Crescent Society of the Islamic Republic of Iran, Tehran, Iran \\ $5 \mathrm{PhD}$ in Heath in Disasters and Emergencies, Department of Health in Disasters and Emergencies, School of Public Health, Tehran University of Medical \\ Sciences, Tehran, Iran \\ 6 MSc in Disaster Management Information Systems, Red Crescent Society of the Islamic Republic of Iran, Tehran, Iran \\ 7 Onco-Surgeon, Shohadaye Tajrish Hospital, Shahid Beheshti University of Medical Sciences, Tehran, Iran \\ $8 \mathrm{PhD}$, School of Allied Medical Sciences, Tehran University of Medical Sciences, Tehran, Iran
}

* Corresponding author: Mehrab Sharifisadeh, Department of Health in Disasters and Emergencies, School of Public Health, Tehran University of Medical Sciences, Tehran, Iran; Research Center for Health Management in Mass Gathering, Red Crescent Society of the Islamic Republic of Iran, Tehran, Iran. Email: mehrabsharifi@gmail.com

Received 2020 0ctober 28; Revised 2020 November 28; Accepted 2021 January 10.

\begin{abstract}
Background: The annual religious ritual of Arba'een is the global largest mass gathering of pilgrims from different countries participating in a mass movement on an 80-km pathway to visit the Shrine of Imam Hussein, the grandson of Prophet Muhammad. The provision of health care for such a mass movement has always been an important vital issue for the health care system.

Objectives: The current study investigated the common illnesses in addition to the quantity of health care services offered by temporary clinics and health stations located on the way to the shrine to such a mass gathering of on-feet pilgrims in Iraq in Arba'een 2019.

Methods: This cross-sectional study was conducted at temporary clinics and health stations where pilgrims in need of nursing, midwifery, and pharmaceutical care were provided with services by general and expert physicians on the way from Najaf to Karbala in Iraq during a week in October 2019.

Results: Imam Reza Temporary Clinic offered services to a total of 26,875 patients, including 9,934 females (36.96\%) and 16,941 males $(63.04 \%)$, on all days of the week. The most common chief complaint reported by the patients were musculoskeletal problems ( $\mathrm{n}=11,945$; $21.99 \%)$, foot blisters ( $n=11,372 ; 20.94 \%)$, and skin lesions ( $n=10,662 ; 19.62 \%)$.

Conclusion: The present study highlighted the need for providing more organized services, especially in emergency health care, and necessity of paying further and closer attention to the significance of the health history of those pilgrims attending such religious mass gatherings in previous years.

Keywords: Arba'een, Mass gathering, OPD, Patients, Temporary clinical care
\end{abstract}

\section{Background}

The World Health Organization (2015) defines mass gathering as the concentration of individuals at a specific location for a particular purpose over a period of time and with the potential to strain the planning and response resources of the country or community (1). It is formed in sports games (2), religious ceremonies (3), political demonstrations, and scientific events (4-6). Such formations experience more exposure to the risk of Human stampede $(7,8)$. Although Hajj, has been previously identified as one of the world's largest mass gatherings (9) several times (3), recently it has been the Arba'een pilgrimage happening to be the largest on-foot religious mass gathering $(10,11)$. In 2019, more than 18 million pilgrims gathered in Iraq during the Arba'een ceremony (10). Pilgrims from all over the world walked to the shrine of Imam Hussein in Karbala that is $80 \mathrm{~km}$ far from the holy Najaf (10).

To ensure a healthy situation for such a mass gathering, health service providers played a major role in the protection of pilgrims in the face of illnesses and health issues. As a consequence, mass gathering medicine as a new health discipline was launched by Ministry of Health in Geneva in May 2014 (5) to address health challenges and issues (12, $13,14)$. Weather conditions and climate changes (15) usually exert severe impacts on different kinds of communicable and non-communicable diseases. That is why the chief medical complaints are reported as infections in various air routes and in water and food by arthropod vectors and rodents (16-18). These issues should be given close consideration in the years to come $(19,20)$.

The health sectors are recognized to play a key role in the reduction of the risk of communicable diseases and health. However, treatment departments,

Copyright (c) 2021, Author(s). This is an open-access article distributed under the terms of the Creative Commons Attribution-NonCommercial 4.0 International License (http://creativecommons.org/licenses/by-nc/4.0/) which permits copy and redistribute the material just in noncommercial usages, provided the original work is properly cited 
including medical care, dentistry, nursing, medicine, and medical emergencies, serve as pioneers of health care along the way. Age and health risk factors showed to have a significant share in the preparedness of the treatment staff and provision of supporting items.

\subsection{Approach}

Ali Ibn Musa al-Reza Clinic as a field hospital is located between Najaf and Karbala about $80 \mathrm{~km}$ far from Karbala. This hospital with 52 voluntary experts received patients free of charge during a week before Arba'een within October $10^{\text {th }}$ to $17^{\text {th }}, 2019$. However, the temporary clinics and stations have 12 physicians, 4 dentists, 1 pharmacy, 18 nurses and midwives, 1 emergency physician, 1 pediatrician, 1 surgeon, 2 health managers in emergencies and disasters, 2 translators, 4 drivers, and service support. The clinics provide services of general, internal, and emergency medicine.

\section{Objectives}

To ensure better future preparedness, this study examined full-time health care services in Ali Ibn Musa al-Reza Temporary Clinic in Iraq in 2019.

\section{Methods}

In this cross-sectional analytic-descriptive study, sampling was conducted among pilgrims referring to temporary health clinics. Health care services offered to these patients were registered according to the evaluation checklist of the Iran hospital evaluation system.

As the first step, the patients were referred for the admission process to be registered followed by triage which was performed by the triage unit. Then, the patients were screened by skilled and experienced nurses. After screening, the nurses referred the patients to a general practitioner, specialist, injection room, and pharmaceutical service centers. For the easy access and convenience of the patients, a ward was allocated to male patients. It was located in the northern part of the clinic. Another ward was planned for female patients. It was in the southern part of the clinic. The pharmacy was located in the middle in order to be easily accessible for both groups.

The demographic characteristics of the patients, including gender, age, cause of referral, and diagnosis, were recorded. The patients received all the services free of charge. The clinics were staffed by 52 treatment and support nurses working 24 hours a day in three rotations of the morning, noon, and night. Patients were distributed into 10 groups based on their age, including infants, children under 5 years of age, children within the age range of 6-12 years, adolescents within the age ranges of 12-18, 18-25, $25-35,35-45,45-55$, and 55-65 years, and the elderly over 65 years of age.

The patients referred to the clinics were diagnosed with gastrointestinal disease, skin lesions (including sweat, heat, bites, burns, and edema), colds and allergies, respiratory infections, kidney diseases, and urinary tract diseases. Diarrhea, trauma, eye infections, heart disease, diabetes, foot blister, ear, nose, and throat (ENT) diseases, gynecological diseases, neurological diseases, and addiction. The daily data were collected by the researchers' team and analyzed using SPSS software (version 18). A descriptive analysis of the diseases among different age groups was carried out. For the ethical and privacy considerations, this study did not ask for the name or identity of the patients in the registration forms. The patients were categorized only by their code of triage. They were separately given health care services by male and female physicians and nurses as a mark of respect for their human and religious rights.

\section{Results}

The results of statistical analysis showed specialized services offered to 26,875 patients, including 9,934 (36.96\%) female and 16,941 $(63.04 \%)$ male subjects, referring to the clinic in the course of one week. The lowest number $(n=2,898)$ of the patients was reported for the first and second days. The maximum number $(n=6,537)$ of the patients showed up on the fifth day (Table 1).

Among 26,875 patients in different age groups, the lowest frequency was reported for the infants $(\mathrm{n}=35 ; 0.13 \%)$. During the one-week service period, the total number of referred women was 9,934. The number of the female patients was lower than the number of male subjects $(n=16,941 ; 63.04 \%)$ (Table 2). The highest frequency $(n=5,941 ; 22.11 \%)$ of referrals belonged to the age group of 45-35 years, the majority of whom were female $(n=3,730$; $62.78 \%$ ) (Figure 1).

Regarding the patients' type of disease, the highest rate was related to musculoskeletal problems with 11,945 cases (including 4,824 females [40.39\%] and 7,121 males [59.61\%]) (Table 3). Nursing services were not fully registered due to the crowded ward and lack of sufficient nursing staff. However, it

\begin{tabular}{|c|c|c|c|c|c|c|c|}
\hline Gender & $1^{\text {st }}$ day & $2^{\text {nd }}$ day & $3^{\text {rd }}$ day & $4^{\text {th }}$ day & $5^{\text {th }}$ day & $6^{\text {th }}$ day & Total \\
\hline Female (n) & 1,033 & 1,399 & 487 & 2,154 & 2,090 & 2,771 & 9,934 \\
\hline Male (n) & 1,865 & 1,880 & 2,725 & 2,539 & 4,447 & 3,485 & 16,941 \\
\hline Total (n) & 2,898 & 3,279 & 3,212 & 4,693 & 6,537 & 6,256 & 26,875 \\
\hline
\end{tabular}




\begin{tabular}{lccc}
\hline \multicolumn{4}{l}{ Table 2. Age distribution of patients referring to Ali Ibn Musa al-Reza Clinic in Iraq in Arba'een 2019} \\
\hline Age group & $\begin{array}{c}\text { Male } \\
\text { n (\%) }\end{array}$ & $\begin{array}{c}\text { Female } \\
\text { n (\%) }\end{array}$ & $\begin{array}{c}\text { Total } \\
\text { n (\%) }\end{array}$ \\
\hline Children & $702(60.52)$ & $458(39.48)$ & $1,160(4.32)$ \\
Adolescents & $1,153(74.82)$ & $388(25.18)$ & $1,541(5.73)$ \\
Young individuals & $2,670(73.43)$ & $966(26.57)$ & $3,636(13.53)$ \\
Middle-aged individuals & $11,884(61.03)$ & $7,588(38.97)$ & $19,472(72.45)$ \\
The elderly & $532(49.95)$ & $533(50.05)$ & $1,065(3.96)$ \\
Total & $16,941(63.04)$ & $9,934(36.96)$ & $2,6875(100)$ \\
\hline
\end{tabular}

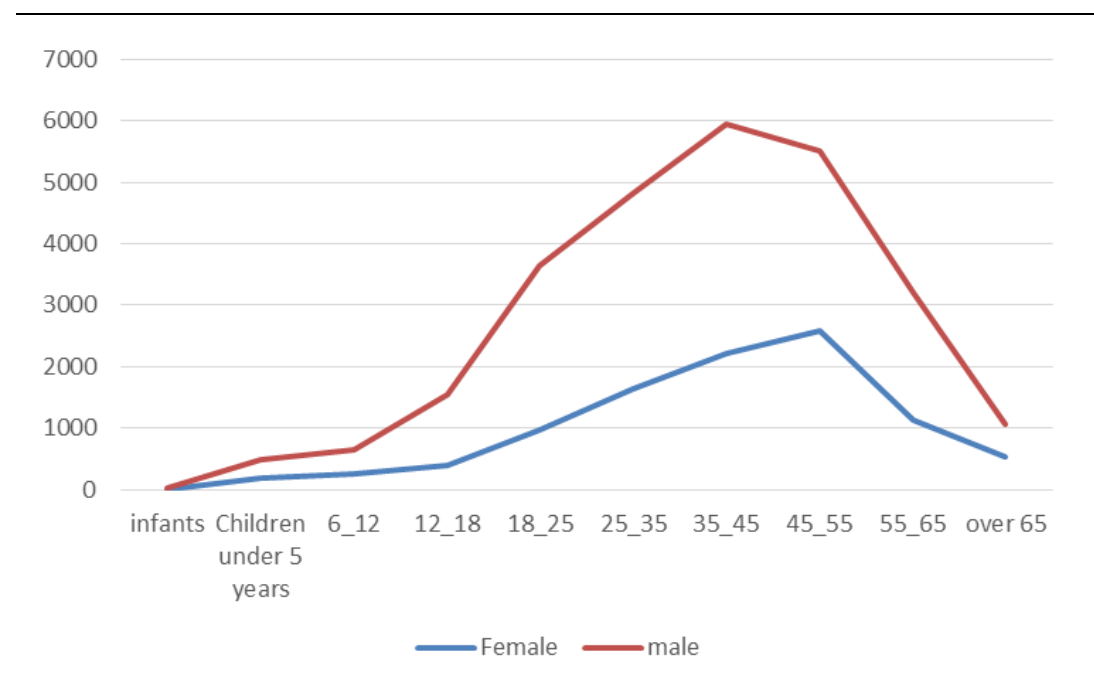

Figure 1. Age distribution of patients referring to the health centers of Ali Ibn Musa alReza Clinic in Iraq in Arba'een 2019

was revealed that the frequency of the female patients was higher than that reported for male subjects due to women's nursing cooperation. The nursing care services for females were 3,195 $(87.17 \%)$ cases. The most frequent services were IM injections $(87.17 \%)$ and the least frequent services were bandage/split (22\%). Furthermore, out of eight patients, five female and three male subjects were transferred to the hospital after stabling due to seizure and heart problems. It is worth mentioning that there was only one case of mental disorders.

\begin{tabular}{|c|c|c|c|}
\hline Outbreaks of diseases & $\begin{array}{c}\text { Female } \\
\text { n (\%) }\end{array}$ & $\begin{array}{l}\text { Male } \\
\text { n (\%) }\end{array}$ & $\begin{array}{l}\text { Total } \\
\text { n (\%) }\end{array}$ \\
\hline Musculoskeletal problems* & $4,824(40.39)$ & $7,121(59.61)$ & $11,945(21.99)$ \\
\hline Fractures & $6(26.09)$ & $17(73.91)$ & $23(0.04)$ \\
\hline Digestive problems & $1,777(35.69)$ & $3,202(64.31)$ & $4,979(9.17)$ \\
\hline Skin lesions* & $3,716(34.85)$ & $6,946(65.15)$ & $10,662(19.62)$ \\
\hline Colds and allergies & $3,191(35.56)$ & $5,783(64.44)$ & $8,974(16.52)$ \\
\hline Respiratory infection & $332(16.64)$ & $1,663(83.36)$ & $1,995(3.67)$ \\
\hline Orology & $233(38.45)$ & $373(61.55)$ & $606(1.12)$ \\
\hline Diarrheal diseases & 302 (38.57) & $481(61.43)$ & $783(1.44)$ \\
\hline Trauma & $51(28.02)$ & 131 (71.98) & $182(0.34)$ \\
\hline Ocular infection & $199(40.12)$ & 297 (59.88) & $496(0.91)$ \\
\hline Cardiac problems & $221(45.10)$ & $269(54.90)$ & $490(0.90)$ \\
\hline Diabetic problem & $180(47.62)$ & $198(52.38)$ & $378(0.70)$ \\
\hline Foot blisters* & $4,200(36.93)$ & $7,172(63.07)$ & $11,372(20.94)$ \\
\hline Ear, nose, and throat & $365(38.22)$ & $590(61.78)$ & $955(1.76)$ \\
\hline Gynecology & $176(44.78)$ & $217(55.22)$ & $393(0.72)$ \\
\hline Neurology and psychiatry & $16(37.21)$ & $43(72.88)$ & $59(0.11)$ \\
\hline Addiction & $10(41.67)$ & $14(58.33)$ & $24(0.04)$ \\
\hline
\end{tabular}

\section{Discussion}

In 2019 , the temporary clinic located on the way from Najaf to Karbala admitted 26,875 patients,
9,934 (36.96\%) and 16,941 (63.04\%) of whom were female and male in a course of one week, respectively. It reflects a higher number of male pilgrims attending the Arba'een mass gathering than 
that of female subjects. The age groups consisted of children ( $n=1,160 ; 4.32 \%)$, adolescents $(n=1,541$; $5.73 \%)$, young individuals $(n=3,636 ; 13.53 \%)$, middle-aged individuals $(\mathrm{n}=19,472 ; 72.45 \%)$, and the elderly $(n=1,065 ; 3.96 \%)$. Reported health complaints were categorized as musculoskeletal problems, fractures, digestive diseases, skin lesions, colds and allergies, respiratory infection, orology diseases, diarrheal diseases, trauma, ocular infection, cardiac problems, diabetic problem, foot blisters, ENT diseases, and gynecology, neurology, psychiatry, and addiction problems.

The results of the present study are similar to the reports presented by other service centers in different areas in Iraq within a specific time period. They also reported that musculoskeletal disorders, blistering heat, respiratory problems, and colds were the main complaints of the patients $(10,21)$. Soltani (2020) (21) also stated respiratory diseases, gastrointestinal and musculoskeletal problems., cardiac diseases, trauma, and trend of health issues in consecutive years which should be considered top priorities for the health systems of countries participating in such a mass gathering ceremony (21). According to the findings, the individuals within the age range of 35-45 years comprised the highest frequency of the patients. It was identified that this period of life is sensitive, particularly for those who live in vulnerable prone areas. Therefore, a proper lifestyle, self-care knowledge, and public health education are also required to ensure a healthy life for these individuals.

Regarding the patients' type of disease, the highest rates were reported for musculoskeletal problems with 11,945 cases (including 4,824 [40.39\%] females and 7,121[59.61\%] males) and fractures among male patients $(n=17 ; 73.91 \%)$. The female patients showed better self-care by taking more rests on the way to the shrine. That is why they experienced lower musculoskeletal problems in comparison to male subjects. It was also observed that non-ergonomic shoes and relatively heavy backpacks could cause a high prevalence of musculoskeletal disorders.

Since non-use of oral rehydration salt (ORS) powder had caused severe muscle cramps in individuals, medical science centers of border provinces were advised to widely distribute powdered ORS packages to pilgrims in the coming years. However, it was shown that in Iran musculoskeletal disorders (MSDs) caused disability (2020) (22) for the population over 50 years during 1990-2017. The aforementioned results confirmed that a low level of back pain is the greatest contributor to disability-adjusted life years (DALYs) due to $4.5 \%$ DALYs. It was observed that the female population experienced a considerably higher burden of MSDs, with years of life lost (YLLs) and years lived with a disability (YLDs) rates of $115 \%$ and $48 \%$ per
100,000 (YLLs=28.7; YLDs=2629.1) individuals in comparison to males (YLLs=13.2; YLDs=1766.1), respectively (22). Contrary to the results of this study, musculoskeletal problems were more common in men $(n=7,121 ; 59.61 \%)$, compared to that reported for women $(n=4,824 ; 40.39 \%)$. Since individuals are all prone to actual back pain, it is important to give attention to such an annoying pain.

Although the majority of the patients experienced musculoskeletal problems, the number of blisters was higher in patients. The reason was running a massage therapy station only the day after the clinic was set up. In the station, the blisters were treated and consequently the blistering statistics reduced. Prolonged walking distance can lead to over-fatigue syndrome, which is a form of musculoskeletal problems. According to findings obtained in Arba'een 2019, most diseases were related to musculoskeletal problems, foot blisters, and skin lesions. Nevertheless, Hajj, as the largest religious gathering after Arba'een, had the highest rate of $50-93 \%$ reported for breathing problems (10). The other health problem was a lack of proper nutrition, especially drinking water and minerals. The consumption of less water and salt, together with excessive sweating caused discomfort among pilgrims.

Other major complaints made by patients were gastrointestinal disorders caused by a lack of awareness of care and hygiene. Furthermore, the supply and distribution of unhealthy meals (10) and consumption of unhealthy drinks can be factors causing digestive problems and gastrointestinal diseases among pilgrims. Although the Iranian Red Crescent Society of the Islamic Republic of Iran actively provides many public and institutional health stations, it has not yet met the scale of existing needs and demands (11).

Skin lesions were considered other common causes of the disease, which were reported in a study by Scholliers (2017) (23) as the most common disease in mass gatherings. Infectious and contagious diseases have been reported in a human stampede in India (Kumbh Mela). There is a need to develop a strong surveillance system for observing pilgrims in Arba'een symbolic trek to identify those with appendicitis, diabetes, hypertension, heart diseases, and endocrine and mental illness vulnerabilities. Health officials need to take preventative measures to coordinate Arba'een walking in the years to come with the heatwave. Actions were taken to monitor and control the trauma caused by traffic accidents through setting up proper road-safety infrastructure.

In the study of epidemiology, Hsieh (2009) (8) believed that the human stampedes are the causes of mortalities and can increase due to high-risk behaviors in mass gatherings, such as sports, religious, music, and political events. The related standard collection of epidemiological data was 
recommended in this regard (8). That is why the measurement and evaluation of the epidemiology of disease would be useful. The examination of previous statistics can be productive for better planning, especially for crowded gatherings as a challenging environment.

In mass gatherings, such as Arba'een, a selfrecording process should be addressed to help with the situation of the inadequate number of personnel with the heavy workload of recording nursing care deliveries. It was also identified that such a religious mass gathering highly demands an integrated system of disaster management measures (9). Preparation and preventive measures in terms of the promotion of public awareness for self-care can also ensure safer and healthier Arba'een on-foot pilgrims in the years to come.

\subsection{Limitations and suggestions}

Due to the low number of nurses, there was no possibility to completely register the details of nursing care services. Crowd, lack of internet access, absence of organized heath registration in Iraq and in border stations, and restrictions in equipment supply were regarded as the main limitations of the present study. Arba'een as the largest religious mass gathering needs to be more organized, especially regarding emergency health care rendering. To prepare and improve health care services, it is essential to document the statistics of previous years and design suitable predictions for future assessments, number of expert allocations, and amount of drug and resource management for the provision of better services. It is necessary to continuously monitor health assessment to identify high-risk groups and requirements for their travel in order to take preparedness arrangement measures by the ministries of health of the two countries for hospital services of level 1, 2, and even 3 .

\section{Conclusion}

In 2019 , the temporary clinic located on the way from Najaf to Karbala admitted 26,875 patients. Reported health complaints were categorized as musculoskeletal problems, fractures, digestive diseases, skin lesions, colds and allergies, respiratory infection, orology, diarrheal diseases, trauma, ocular infection, heart problems, diabetic problems, foot blisters, ENT diseases, and gynecology, neurology, psychiatry, and addiction problems. Different groups of individuals consisting of children to the elderly received health care services. To be more prepared for the next mass gatherings and future Arba'een ceremonies, further organized services, particularly in emergency health care, are highly required. It is also necessary to give further and closer focus on the significance of the health history of patients.

\section{Acknowledgments}

The authors would like to express their gratitude to all physicians, nurses, and health volunteers for their cooperation in the data collection.

\section{Footnotes}

Authors' Contribution: L.M, M.S, H.C, and F.M conceived and designed the experiments. L.M, H.L, and M.S performed the experiments. L.M analyzed and interpreted the data and materials and wrote the manuscript. L.M, M.S, and F.M revised the manuscript. Conflict of Interests: The authors declare that there is no conflict of interest.

Funding/Support: This study was supported by the Health City Company of Tehran Municipality, Tehran, Iran.

Informed consent: All the patients were informed about the research process and objectives. Moreover, informed consent was obtained from all the participants.

\section{References}

1. World Health Organization. Public health for mass gatherings: key considerations. Geneva: World Health Organization; 2015.

2. McCloskey B, Endericks T, Catchpole M, Zambon M, McLauchlin J, Shetty N, et al. London 2012 olympic and paralympic games: public health surveillance and epidemiology. Lancet. 2014; 383(9934):2083-9. doi: 10.1016/S0140-6736(13)62342-9. [PubMed: 24857700].

3. Memish ZA, Zumla A, Alhakeem RF, Assiri A, Turkestani A, Al Harby KD, et al. Hajj: infectious disease surveillance and control. Lancet. 2014;383(9934):2073-82. doi: 10.1016/ S0140-6736(14)60381-0. [PubMed: 24857703].

4. Zeitz KM, Tan HM, Grief M, Couns P, Zeitz CJ. Crowd behavior at mass gatherings: a literature review. Prehosp Disaster Med. 2009;24(1):32-8. doi: 10.1017/s1049023x00006518. [PubMed: 19557955].

5. Memish ZA, Steffen R, White P, Dar O, Azhar EI, Sharma A, et al. Mass gatherings medicine: public health issues arising from mass gathering religious and sporting events. Lancet. 2019;393(10185):2073-84. doi: 10.1016/S0140-6736(19) 30501-X. [PubMed: 31106753].

6. Illiyas FT, Mani SK, Pradeepkumar A, Mohan K. Human stampedes during religious festivals: a comparative review of mass gathering emergencies in India. Int J Disaster Risk Reduct. 2013;5:10-8. doi: 10.1016/j.ijdrr.2013.09.003.

7. Ngai KM, Burkle FM, Hsu A, Hsu EB. Human stampedes: a systematic review of historical and peer-reviewed sources. Disaster Med And Public Health Prep. 2009;3(4):191-5. doi: 10.1097/DMP.0b013e3181c5b494. [PubMed: 20081414].

8. Hsieh YH, Ngai KM, Burkle FM, Hsu EB. Epidemiological characteristics of human stampedes. Disaster Med And Public Health Prep. 2009;3(4):217-23. doi: 10.1097/DMP.0b013e 3181c5b4ba. [PubMed: 20081418].

9. Manoochehry S, Rasouli HR. Recurrent human tragedy during Hajj. Int J Travel Med Global Health. 2017;5(1):36-7. doi: 10.15171/ijtmgh.2017.07.

10. Al-Ansari F, Al Ansari M, Hill-Cawthorne GA, Abdulzahra MS, AlAnsari MB, Al-Ansari B, et al. Arbaeen public health concerns: a pilot cross-sectional survey. Travel Med Infect Dis. 2020; 35:101546. doi: 10.1016/j.tmaid.2019.101546. [PubMed: 31838209].

11. Albujeer AN, Almahafdha A. Does Arbaeen event is taking its place in global mass gathering programs? J Contemp Medi Sci. 
2018;4(2):1.

12. Bullock M, Ranse J, Hutton A. Impact of patients presenting with alcohol and/or drug intoxication on in-event health care services at mass-gathering events: an integrative literature review. Prehosp Disaster Med. 2018;33(5):539-42. doi: 10.1017/S1049023X1800078X. [PubMed: 30208984].

13. Aitsi-Selmi A, Murray V, Heymann D, McCloskey B, Azhar EI, Petersen E, et al. Reducing risks to health and wellbeing at mass gatherings: the role of the Sendai Framework for Disaster Risk Reduction. Int J Infect Dis. 2016;47:101-4. doi: 10.1016/j.ijid.2016.04.006. [PubMed: 27062983].

14. David S, Roy N. Public health perspectives from the biggest human mass gathering on earth: Kumbh Mela, India. Int J Infect Dis. 2016;47:42-5. doi: 10.1016/j.ijid.2016.01.010. [PubMed: 26827807].

15. Patz JA, Epstein PR, Burke TA, Balbus JM. Global climate change and emerging infectious diseases. JAMA. 1996;275(3):217-23. [PubMed: 8604175].

16. Semenza JC, Menne B. Climate change and infectious diseases in Europe. Lancet Infect Dis. 2009;9(6):365-75. doi: 10.1016/ S1473-3099(09)70104-5. [PubMed: 19467476].

17. Cramer W, Guiot J, Fader M, Garrabou J, Gattuso JP, Iglesias A, et al. Climate change and interconnected risks to sustainable development in the Mediterranean. Nature Climate Change.
2018;8(11):972-80. doi: 10.1038/s41558-018-0299-2.

18. Caminade C, McIntyre KM, Jones AE. Impact of recent and future climate change on vector-borne diseases. Ann $N$ Y Acad Sci. 2019;1436(1):157-73. doi: 10.1111/nyas.13950. [PubMed: 30120891].

19. Patz JA. Altered disease risk from climate change. Ecohealth. 2018;15(3):693-4. doi: 10.1007/s10393-018-1382-x. [PubMed: 30377877].

20. Lopez D, Sekaran G. Climate change and disease dynamics-a big data perspective. Int J Infect Dis. 2016;45:23-4. doi: 10.1016/j.ijid.2016.02.084.

21. Soltani A. The necessity of health-centered research in Arbaeen mass gathering. Iran Red Crescent Med J. 2020;22(1):e101174. doi: 10.5812/ircmj.101174.

22. Shahrezaee M, Keshtkari S, Moradi-Lakeh M, Abbasifard M, Alipour V, Amini S, et al. Burden of musculoskeletal disorders in Iran during 1990-2017: estimates from the Global Burden of Disease Study 2017. Arch Osteopor. 2020;15(1):103. doi: 10.1007/s11657-020-00767-8. [PubMed: 32651719].

23. Scholliers A, Gogaert S, Veegaete AV, Gillebeert J, Vandekerckhove $\mathrm{P}$. The most prevalent injuries at different types of mass gathering events: an analysis of more than 150,000 patient encounters. Prehospital Disaster Med. 2017;32(S1):S136. doi: 10.1017/S1049023X17003788. 